\section{La literatura y el fútbol en Chile: entrevista con Roberto Fuentes}

Literature and football in Chile: interview with Roberto Fuentes

\section{Gustavo Cerqueira Guimarães}

Universidade Federal de Minas Gerais (UFMG), Belo Horizonte/Brasil Doutor em Teoria da Literatura e Literatura Comparada, UFMG gustavocguimaraes@hotmail.com

Conheci Roberto Fuentes (Santiago, 1973) por meio da antologia Por amor a la pelota: once cracks de la ficción futbolera (2015), ${ }^{1}$ organizado por Shawn Stein e Nicolás Campisi. Este livro, também em formato e-book, reúne onze contistas que representam os dez países que integram a Conmebol, além do México. ${ }^{2}$ o conto "Un huevón más" é a sensível contribuição

\footnotetext{
${ }^{1}$ STEIN, Shawn; CAMPISI, Nicolás. (Orgs.). Por amor a la pelota: once cracks de la ficción futbolera. Santiago: Cuarto Proprio, 2015.

${ }^{2}$ Autores da antologia Por amor a la pelota: Selva Almada (Argentina), Edmundo Paz Soldán (Bolívia), Sérgio Sant'Anna (Brasil), Roberto Fuentes (Chile), Ricardo Silva Romero (Colômbia), José Hidalgo Palla-
}

de Fuentes, que narra o cotidiano dos meninos em torno das partidas de futebol do bairro - o jogo da vida. Um deles, o Pato, é portador da síndrome de Down. "Él tenía unos veinte años, pero demostraba catorce. Era bajo, gordo, casi no se le notaba un cuello, su boca siempre estaba abierta y parecía feliz", diz no início do conto o narrador, que também é um dos peladeiros da rua.

Quando fui a Santiago para assistir ao jogo do Atlético (El Minero) contra o Colo-Colo pela Libertadores da América de 2016, pensei em procurar o Roberto para realizar uma entrevista com o intuito de saber informações sobre a relação das artes com o futebol no Chile, especialmente com a literatura. Poucas semanas antes de viajar, eu o encontrei no Twitter, trocamos e-mail e, depois, WhatsApp. Toda a comunicação fluiu muito bem. Na segunda-feira, 07 de março de 2016, no final da manhã, Roberto estava gentilmente a minha espera numa estação de metrô para irmos até sua casa caminhando.

res (Equador), Juan Villoro (México), Javier Viveros (Paraguai), Sergio Galarza (Peru), Carlos Abin (Uruguai) e Miguel Hidalgo Prince (Venezuela). 
Ele estava só. Tomamos café e gravamos nossa conversa de aproximadamente cinquenta minutos. $\mathrm{O}$ meu portunhol deu mais trabalho aos transcritores Circe Clingert e Vinícius Cruz - 1ํㅡ versão -, do que ao Roberto, pois ele me compreendia facilmente, já tinha visitado o Brasil por duas ou três ocasiões, além de ter muito interesse pela música e futebol brasileiros.

Roberto é torcedor do Colo-Colo, o que tornou nossa conversa ainda mais interessante. Afinal, nós estaríamos em lados opostos das arquibancadas do estádio no jogo que se realizaria no dia 10 de março. Com muito entusiasmo, ele falou de sua identidade mapuche, representada pelo índio no escudo do time, da maneira como o futebol fez e faz parte de sua vida e como esse jogo está presente no mundo de seus personagens.

A conversa durou mais três horas sem o gravador ligado, Roberto contou outras curiosidades sobre a história de seu clube enquanto almoçávamos e tomávamos café ao som do rádio ligado ao fundo. No fim das contas, para quem gosta, falar de futebol, além de ser muito prazeroso, é um compromisso político e, no caso, igualmente estético.

\section{Gustavo Cerqueira Guimarães - ¿Roberto, qué influencia e importancia el fútbol tiene en su vida? Probablemente es algo que te sigue desde tu infancia...}

Roberto Fuentes - El fútbol siempre ha estado en mí, de dis-

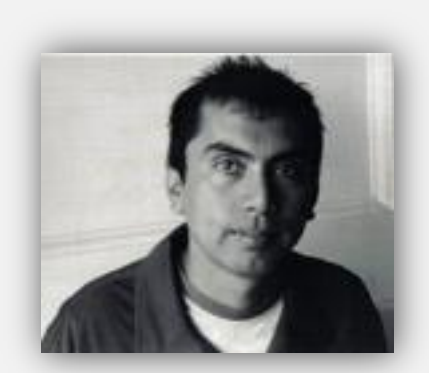
tintas maneras. Desde niño yo vivía en un barrio, una población y pasábamos todos el día, todo el día jugando a la pelota como decíamos acá. Siempre fui hincha... torcedor de Colo-Colo desde niño y de ahí, pero nunca me he separado del fútbol. Siempre jugué de forma amateur, jugué en el barrio, en la universidad, con amigos hasta el día de hoy sigo haciéndolo. Me gusta verlo por televisión, me gusta ir a la cancha, al estadio. El fútbol tiene para mí una identificación especial. Yo vengo de un barrio muy popular, muy pobre y ahí todos eran hinchas del Colo-Colo que es el equipo más popular de Chile. Y para mí ser de Colo-Colo ahora es un poco seguir conectado con ese mundo. Si bien no voy a la galería, al estadio, dónde se encuentran las barrabravas, sino que voy al Océano que es la tribuna y estoy más tran- 
quilo por eso. Pero para mí el fútbol y ser hincha de Colo-Colo es un poco eso mi conexión con mi proprio yo, mi pasado conmigo mismo, con mi barrio, con los amigos antiguos, con jugar en el barrio y eso que creo que es importante no perderlo.

\section{¿De qué manera esa experiencia afecta su literatura?}

Como todo escritor, toda mi experiencia están ahí escrita, están transmitida. A mí me gusta mucho el cine, me gusta la literatura, me gusta leer libros, me gusta ir al teatro, me gusta la opera... incluso hace poco. Pero en el mismo nivel está el fútbol. 0 sea, a mí me gusta tanto como ir al Teatro Municipal a ver una ópera clásica, como me gusta ir a ver a Colo-Colo contra San Luís al Monumental, como me gusta ir a ver a una película de Spielberg. Entonces para mí es parte de mi identidad. Y como parte de mi identidad está presente en forma inconsciente. De hecho, a veces la gente como tú, me habla de que el fútbol aparece en mi literatura, y se interesa, claro y de ahí me doy cuenta. Pero no es que yo me siente y diga: "voy a escribir sobre fútbol, voy a escribir una novela que hable de fútbol, no, no". Escribo una novela que hable sobre un amor perdido, la represión en la dictadura en Chile en los 1980, y el fútbol siempre estará ahí de alguna manera. Por eso que para mí el fútbol es tan importante como cualquier arte, por decirlo de alguna forma. Es parte de mí. No lo puedo separar.

\section{¿Y cuáles son sus obras que hablan de fútbol, aunque de manera indirecta?}

La novela Algo más que esto [2004]... hay un cuento que se llama "Pato en la Laguna" que hay una crisis familiar entre medio de un partido de Colo-Colo muy importante. "Un huevón más" ha sido el cuento más publicado que tengo, está entre los mejores cuentos chilenos del siglo XXI, que habla un poco sobre la integración, sobre la inclusión de un niño con síndrome de Down a través del fútbol de barrio. Bueno, en mis novelas en otros cuentos también aparecen. Hay un cuento que habla sobre un niño [y fútbol] que aparece en mi primero libro de cuentos Está mala la cosa afuera [2002] y hay muchos cuentos que yo escribí sobre mi barrio cuando éramos chicos, dónde aparece mi pandilla. Y ahí aparece el fútbol siempre, en esa colección en particular hay más que en otras. 
No tengo ningún cuento como especifico o alguna novela específica que yo me he planteado a escribir sobre fútbol, pero si, aparece siempre en general en mi narrativa. Mi único libro de no ficción se llama Síndrome de Down: historia de un superhijo [2011], que hablo de la experiencia de ser papá de un niño con síndrome de Down, es como crónicas y está estructurado casi como novela, y hay un lazo entre padre y el hijo que se hace más fuerte a través del fútbol, justamente. ¿Por qué que sueña un papá cuando tiene un hijo varón, generalmente...?

\section{¿Que sea colo-colino...?}

Claro... que sea colo-colino, que jugué la pelota... Pablo fue un par de años a la escuela de fútbol de Colo-Colo, después no quiso ir. Se vestía y jugaba con los demás niños...

\section{¿Cómo el personaje de “Un huevón más"?}

Claro... y jugaba, yo iba con él y todo... hasta el día de hoy jugamos a la pelota un poco. Él no va a poder practicar de forma profesional, claramente, no le gusta ir al estadio... me he dicho que cuando sea más grande me va a acompañar. Así, que estoy esperando ese día para vestirlo de blanco e ir al estadio. Pero ese es el libro que quizá aparece un poco más... si viene el tema de otro, el tema de cómo ser papá, y la llegada de este hijo. El fútbol aparece como un elemento unificador en esta relación.

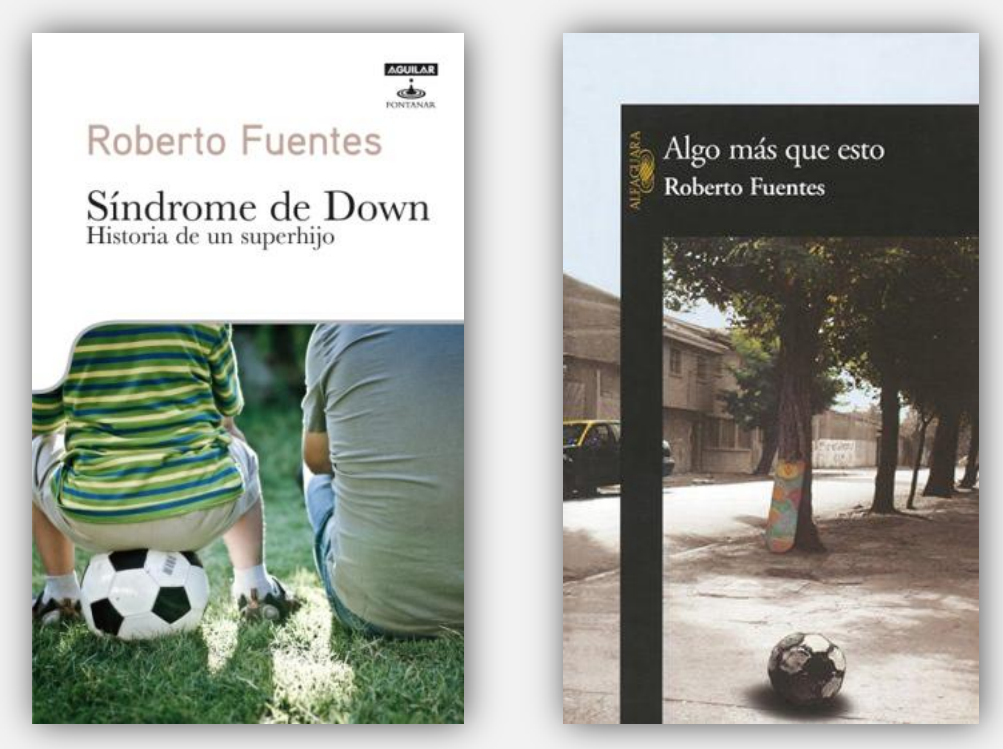

¿Fuiste invitado por los organizadores de la antología Por amor a la pelota en que están uno de cada país de la Conmebol y uno invitado que es mexicano, cómo ocurrió esta invitación? 
Sobre el libro en cuestión... me invitaron los editores. Ellos leyeron literatura chilena, buscaron y de hecho vieron a un par de cuentos míos. "Pato en la laguna” y “Un huevón más” y le gusto más ese. Y me invitaron lo que me sorprendió. Tengo una carrera, catorce quince libros publicados... pero no soy tan conocido. Entonces que me venga alguien de los Estados Unidos y también hay un editor que está en Estados Unidos pero que es argentino, y que me diga que el cuento de fútbol que más le ha gustado de un autor chileno, para mí fue sorprendente gratamente, me pone feliz.

\section{¿Cómo el fútbol está representado en la literatura chilena?}

Chile en general no se escribe mucho sobre fútbol. Lo que he leído de la literatura chilena no he visto muchas cosas. En narrativas sí que he visto algunas cosas, Hernán Rivera Letelier escribió sobre un mundo popular minero en el norte de Chile y de repente de hecho tiene una novela que se llama "El fantasista", que es sobre un jugador de fútbol muy hábil, pero en él es lo me mas me acuerdo. Pero también Alejandro Zambra tiene un par de cuentos creo que habla sobre fútbol, pero he visto muy poco. Hernán Rivera Letelier tiene al igual que Zambra y yo que viene de barrios populares. Quizá el escritor chileno que viene de un sector un poco más acomodado nunca toca el fútbol en general. Nunca lo toca para nada. Se da la coincidencia entre estos autores que tocamos el tema del fútbol el tema sobre nuestro origen más proletario y claro el fútbol está claramente ligado a eso también, o sea para jugar fútbol solamente no bastan zapatos. Y puedo jugar a pie pelado en un cacho de tierra yo creo que por ahí está la relación.

\section{¿En Brasil tenemos Nelson Rodrigues como un cronista} del fútbol, donde la narración no es solo sobre cuestiones taticas pero el jugador es un personaje, hay algo parecido o alguna influencia de eso en Chile?

Yo Creo que en Chile se está dando recién. Ahora que Chile está más entrado en el fútbol, menos que en Brasil, creo yo... y que Argentina y Uruguay yo creo y que por eso en esos países se da una relación más directa entre literatura, crónica y fútbol. Más que Chile. Pero en Chile ha empezado ahora. Hay un libro de un periodista que se llama Cristian Arcos, que saco 
a propósito del mundial, y que tiene estos libros como de investigación, de crónicas. Tiene uno sobre el mundial, sobre la copa América de Chile y tiene también uno sobre la historia de Gary Medel, que es muy interesante, es el libro más literario que tiene, porque habla de la vida de un jugador símbolo, que juega en el Inter ahora... de Milán, un defensa central, que mide uno sesenta, pero muerde. Y ahí otro autor, en general son periodistas los que están muy cercanos de la literatura, que admiran y que leen mucha literatura. Que se han atrevido a escribir sobre fútbol más... estos últimos 3, 4 años. Y ahora se aparecen en librería, libros sobre eso que lo encuentran interesante. Pero antes... hay muy poco. No había una tradición. Yo creo que recién están haciendo en Chile una tradición sobre literatura, crónica y fútbol.

\section{¿Pero es el deporte más importante en Chile también, no?}

Sí, claro... Es el deporte más importante, el más masivo, lejos, lejos... sí.

\section{Cuéntanos un poco de tu trayectoria como hincha, aficio-} nado de Colo-Colo.
De niño mi papá me llevaba al estadio. Yo tengo recuerdo de los cinco años en el Estadio Nacional. Colo-Colo jugaba en el estadio en los años 1978. Empecé a ir en los 1977 con los cuatro años, no me acuerdo, yo me acuerdo de los 1978 adelante. Y siempre había como un ritual en la casa los domingos: arreglar el pan con huevo, jugo. Para mí el domingo giraba en torno de la posibilidad de ir al estadio. Llegaba mi tía, hablaba conmigo, me daba plata. Mi papi juntaba y me llevaba al estadio, tomábamos un micro, un bus, cruzábamos la ciudad, y llegábamos. Hasta el día de hoy, el olor a cigarro, para mí... yo no fumo pero, el olor a cigarro a mí me recuerda el estadio. Ando en la calle y siento olor a cigarro, porque cundo yo iba al estadio... se podía fumar en el estadio en esa época, pero se sigue fumando. Entonces, ahí tiene para mí una conexión, con mi infancia. Siempre jugué, siempre fui hincha de Colo-Colo, empecé a salir solo al estadio a los doce o trece años. Mi papi no quería ir, iba yo, y después seguí yendo. Y ahora, estando en la universidad, siendo joven... ya estoy abonado, que se llama, como para todo el año y siempre voy, tengo amigos, muy amigos, que van al estadio. Casi un encuentro también, 
nuestra cita quincenal al estadio. Nos ponemos en día y conversamos. Yo siempre he sido colo-colino de chico, desde pequeño y bueno, hasta la muerte no creo que cambie nada. Me acuerdo de la película argentina El secreto de sus ojos, que gano el Oscar... no sé si la viste. En la película hay un asesino que comete una violación, un asesinato, se cambia de identidad, se va de barrio, de todo. Pero lo único que no cambia, es ser hincha de Racing, ¿y cómo lo ubican?... en el estadio. Entonces...

\section{Sí, una imagen maravillosa, la cámara se acerca al estadio desde la parte superior, acercándose hacia el interior.}

Eso mismo. No sé cómo le hicieron, yo hasta el día de hoy no sé cómo le hicieron esa imagen. Pero increíble un poco eso. Uno puede cambiar de barrio, puede cambiar de señora, de esposa, puede cambiar de ciudad, puede cambiar de todo, pero no va a cambiar de ser hincha de fútbol. Para mí, como te decía, Colo-Colo tiene una identificación muy fuerte con dos temas. Uno con el tema popular, con el tema de mi origen, y otro con el tema mapuche. Aquí en Chile, el estado, en general, independiente del gobierno, ha tratado muy mal el pueblo mapuche. Y Colo-Colo fue mapuche, así hay siempre una identificación. Yo tengo una bandera colo-colina, yo tengo una bandera mapuche, a veces con la cual voy al estadio. Ser hincha de Colo-Colo tiene un componente nostálgico, tiene un componente hasta político también, social, tiene un componente étnico.

\section{¿Hablando de películas, hay representaciones del fútbol en otras artes en Chile?}

Hay una película de Andrés Wood, Historias de fútbol [1997]... En la música popular hay un grupo punk que se llama Los Miserables, hicieron un disco entero de fútbol que habla sobre el fútbol y sobre la canción. Bueno... ese grupo siempre está muy cercano al pueblo. Y yo creo que salió la motivación en forma natural. No es mucho lo que hay. Incluso hay un brasilero, [Joe Vasconcellos], nacionalizado chileno, que tiene una canción llamada "Sed de gol". Pero también no se da mucho, se da más que nada a nivel popular.

\section{¿En la música popular hay homenaje a Colo-Colo por ejemplo?}


No, No he visto mucho. Hay grupos que están como más identificados con algún club, eso sí he visto. Cuando Colo-Colo gano la Libertadores quizás aparecen cosas... pero no hay como un seguimiento. Como una cultura de música y fútbol en Chile. El cine hay algo más he visto, un poco más... en teatro, no. Y en otra arte mayores o distintas no he visto. Yo creo que el trabajo artístico es un poco de elite. Independiente del área, puede ser cine, puede ser pintura, puede ser teatro, puede ser música. Entonces eso mismo lo aleja, de ciertos temas populares y el fútbol es uno de ellos, no digo que no exista lo otro, o se da mucho más en ese sentido. No recuerdo Pablo Neruda escribir sobre fútbol o ir al estadio alguna vez. Hay un autor argentino que siempre va al estadio. Pero de autores chilenos no, son pocos los que he visto. En el estadio ninguno. Son pocos los que tocan el tema. No hay una cosa fuerte en eso.

\section{¿Hay algo que te gustaría decir para nuestros lectores como cierre de nuestra entrevista?}

El fútbol en general para mí... yo soy hincha de corazón, pero tampoco me gusta que se utilice como para... como para ex- presar ciertos odios. Por ejemplo, el fútbol es muy machista, aquí los hinchas del Colo llaman los hinchas de la U de madres y los hinchas de la Católica de monjas, porque están ligados a la iglesia católica. Los insultos son femeninos, siempre femenino.

\section{Como en Brasil, cuando los atleticanos, los mineros, dicen} a los cruzeirenses: las Marias.

Claro, es como que al decirlo de forma femenina el insulto se supone que se agudiza.

\section{Es una cosa menor...}

Y una cosa misógina, y homofóbica también. Eso en su caso de llamar maricón al hincha rival... que parecen mujeres... eso me molesta mucho. Me gusta el tema de la burla pero respetuosa - "Te ganamos", "siempre hemos ganado". Yo creo que es parte del fútbol, pero no creo que no se deba utilizar como para insultar al hincha colo-colino, al hincha de la U, que es muy popular igual que la Colo-Colo le dicen palabras que son apelativas. Los insultos también son muy clasistas. Entonces todo eso del fútbol a mí me molesta de verdad. Trato de hacer 
un poco de escuela. Yo tengo amigos que cuando empiezan con eso, yo les digo "... ah por favor”.

Dado que el ser humano tiene un componente sádico y masoquista, ¿no te parece que los estadios son un lugar de expresión?

Juego fútbol todos los lunes y claro... de repente, me enojo jugando. Y claro por más que uno lo raciocine. A veces claro, que te pasa. Porque el fútbol es agresivo. Nosotros jugamos con jóvenes... y muchas veces le ganamos. Porque nos paramos más firme en la cancha. Ellos corren, son hábiles y todo. Agarramos más firme a la pelota, más decididos, y eso da cierto respeto, no empiezan a hacer locuras. Dan cierta distancia y a veces nos imponemos a eso, mas empujamos un poco, pero yo también no soy de pegar así. Pero yo soy firme. Y sí, pienso que sirve como válvula de escape de eso que tenemos todos, de eso que tiene el ser humano y que necesita de alguna manera que escape por algún lado.

En los estadios de fútbol también oímos expresiones de racismo y xenofobia...
Sí, xenofobia sí. En el juego del partido de Colo-Colo contra el Minero van a gritar maricón. Todo el estadio saltando. Yo no salto, de verdad. Van a gritar negro. Porque hay mucha gente de color en el equipo seguramente van a gritar. Lo que es una tontería.

Parece una utopía, pero si pensamos de la siguiente manera: en el estadio podemos gritar y insultar, pero no en las calles. Pero es difícil saber la medida...

Sí, creo que es un poco utópico también... La gente está en el estadio e insultan a un jugador de marica y negro y lanzan una banana para lo molestar. Lo mejor mismo es parar, pelar y comer la banana, como lo hizo el jugador del Barcelona [Daniel Alves]. La situación fue interesantísima. Hay gente que incluso por las redes sociales, me dicen indio maricón. Porque soy hincha de Colo-Colo. Indio mapuche está bien, orgulloso. ¿Maricón? Bueno, si tú crees que soy gay, da lo mismo bien. No me ha dicho ningún insulto.

Para terminar nuestra grabación, di lo que quieras sobre el fútbol... 
El fútbol es el gran evento que reúne a la gente, mucha gente, sobre todo de los sectores populares, va a la cancha los domingos con la familia incluso, con los niños. Algunos se quedan viendo a través del televisor. Entonces, creo que lo importante utilizar esta herramienta tan poderosa en cosas buenas, incluso como tema educativo. La misma escuela de fútbol que se colocan en barrios populares sirve mucho para alejar los chicos de la droga, ese tipo de cosa. Yo creo que en el fondo hay que impulsar el deporte en general, pero con mucho respeto a la vez. Creo que el fútbol es ideal para que creamos atletas, creamos hinchas, que creamos cierta pasión, pero... no sirve de nada si no existe respecto. La idea no es crear energúmenos ni gorilas, la idea es crear personas, personas, yo creo que el fútbol sirve mucho para eso, porque el fútbol en el fondo es una metáfora de la vida. En el fútbol, uno sólo no se hace nada tiene que estar con diez compañeros. Una persona no anda sola por la vida. Está el rival entre comillas. Y que se juega y siempre en la vida uno está, como ciertos desafíos, desafíos educacionales, personales donde se gana o pierde.

\section{Hay un cronista brasileño [Armando Nogueira] que dice que el hombre es un animal social cuando pasa la pelota...}

Claro, creo que el fútbol es una gran metáfora de la vida y, en ese sentido hay que cuidarla. Porque el fútbol se puede transformar solamente en una válvula de escape, de violencia, y no creo que sea saludable. Si no lo vamos matando el fútbol, también está el tema con el dinero. El fútbol mueve mucho dinero y eso es innegable. Vivimos en países capitalistas, casi imposible salirse de eso. Por lo tanto donde hay mucho dinero hay mucho poder, como en el tema de la FIFA y mucha corrupción. Por ejemplo, mi equipo Colo-Colo tiene una sociedad anónima que se llama Blanco y negro, tienen derecho de Colo-Colo y que ven al equipo como un activo. Los jugadores son empleados, pero yo no soy hincha blanco y negro. Para mí, si la empresa que maneja el blanco y negro tiene problema económico da lo mismo. A veces la gente confunde, de repente hay un juicio contra blanco y negro que son algo mal y dicen: “no, tan perjudicando Colo-Colo". No están perjudicando ColoColo. Están perjudicando a blanco y negro, Colo-Colo es otra cosa. No es eso, es mucho más que eso. Entonces, yo creo que 
hay que separar las cosas. Pero bueno... claramente hay una relación económica y me gustaría que además hablando del fútbol sud americano, que los chicos lo cuidaran un poco más. A los chicos, las estrellas, que jugaran un poco más acá antes de irse. Tienen dieciséis o diecisiete años y se van. Vuelven con treinta y tanto años cuando están gordos y todo. Cuando no estaba tan globalizado el mundo, cuando los chicos terminaban haciendo toda su carrera en su país iban cuando ya estaban bien consolidados en su equipo. Ahora, no, porque llevan una nueva oferta y como la necesitan plata. Pero no es lo mismo que alguien que ha estado cuatro o cinco años en el club. Bueno, todos los clubs son distintos pero... Hay clubes que tiene como que cierta cercanía con su hincha mucho más que otros. Yo ya sabía que el Atlético Mineiro es un club más popular, los hinchas van a la cancha siempre. Y Colo-Colo es difícil jugar, ¿Cree que el jugador se va a dominar en la cancha solo por tener un nombre? No. Los hinchas quieren que los jugadores corran con gana por su club, aplauden y gritan. Algunos jugadores no entienden eso y no se identifican con el Colo-Colo, no entienden lo que busca el hincha verdadero, el hincha que siempre va al estadio. Entonces, el fútbol es un mundo, un mundo que hay muchos por ver y por aprender.

\section{"Es una gran suerte no saber con exactitud en qué mundo} vivimos"...

Claro, ese es un gran un poema de la [Wisława] Szymborska, la segunda mujer a ganar un Nobel, la primera fue Gabriela Mistral, la chilena, gran poeta. Eso se da en todo, en la vida y en el fútbol. Bueno, porque eso nos permite seguir buscando.

Santiago, 07 de março de 2016.

Transcripción:

Circe Clingert: Vinícius Pereira de Souza Cruz. 